\title{
PASIVOS AMBIENTALES: UN PROBLEMA [INTER-INTRA] GENERACIONAL
}

\author{
ENVIRONMENTAL LIABILITIES: A PROBLEM [INTER-INTRA] GENERATIONAL
}

Georgina Doroni

(Universidad Nacional de Córdoba / Argentina)

georginadoroni@gmail.com

Recibido: 18/09/2018

Aprobado: 30/10/2018

Deberían exasperarnos las enormes inequidades que existen entre nosotros, porque seguimos tolerando que unos se consideren más dignos que otros [...] Seguimos admitiendo en la práctica que unos se sientan más humanos que otros, como si hubieran nacido con mayores derechos ${ }^{1}$.

\section{RESUMEN}

A través del presente trabajo se analiza la necesaria relectura e interacción entre los derechos humanos y el derecho ambiental a los fines de garantizar y fortalecer la incorporación de la dimensión colectiva o social. A partir de la obligación imperativa que "el daño ambiental generará prioritariamente la obligación de recomponer" ${ }^{2}$ se aborda la problemática de los pasivos ambientales, que (en algunos casos) debe ser resuelta por el Estado para evitar seguir traspasándolos a las generaciones futuras. Se analiza el derecho de reparación integral y garantía de no repetición como medidas para abordar las inequidades en la distribución de las cargas y costos socio-ambientales de una contaminación histórica que es arrastrada hacia tiempos presentes y se manifiesta como un potencial problema para las generaciones futuras, lo que requiere de una interpretación hermenéutica del complejo engranaje de sistema de fuentes.

Palabras claves: derecho humano- medio ambiente- garantía de no repetición- reparación integral- remediación.

\section{ABSTRACT}

This work analyzes the necessary re-reading and interaction between human rights and environmental law in order to guarantee and strengthen the incorporation of the collective or social dimension. From the imperative obligation that "environmental damage will primarily generate the obligation to recompose" addresses the issue of environmental liabilities, which must be resolved by the State to avoid further transferring them to future generations. It analyzes the right of integral reparation and guarantee of non-repetition as measures to address inequalities in the distribution of socio-environmental costs and burdens of a historical contamination that is drawn to present times and manifests itself as a potential problem for future generations, through a hermeneutic interpretation of the complex system of sources.

Keywords: human right- environment- integral reparation- assurances of non-repetitionremediation.

\footnotetext{
${ }^{1}$ Francisco: Encíclica Laudato Sí, nota 90.

${ }^{2}$ Según texto del artículo 41 de la CN.
} 


\section{Introducción}

Podemos afirmar la necesaria relectura e interacción entre los derechos humanos y el derecho ambiental; una visión integrada y armoniosa entre el sistema de derechos humanos y el medio ambiente resulta a todas luces imperiosa y conveniente, a los fines de garantizar y fortalecer la incorporación de la dimensión colectiva o social del derecho humano al medio ambiente sano (Morales Lamberti: 2015: 148).

como base de una integración e interpretación hermenéutica de las obligaciones que se derivan a los Estados en la concreción y protección del derecho humano al ambiente; ambiente que se revela como medio y entorno vital no sustituible, como "base física que materializa la posibilidad de otros derechos humanos y frecuentemente no reparable en su integridad en caso de daño, refuerza la inevitable interconexión entre el ambiente y los derechos humanos" (Pezzano, Doroni, 2017) ${ }^{3}$.

En este contexto, se plantea la problemática de la remediación de los pasivos ambientales ${ }^{4}$, que debe ser resuelta por el Estado, quien si bien no fue el generador del PA, debe brindar soluciones para evitar seguir traspasando los problemas a las generaciones futuras, atento la alta incidencia social del problema. El concepto de PA

tiene importancia social, en tanto que su existencia, cuantificación y necesidad de remediación se está afirmando cada vez más en diferentes contextos de lucha de la sociedad civil y colectivos sociales. Desde una dimensión social, una primera relación que aparece evidente en el tema de pasivos ambientales y sitios contaminados es con la pobreza: estos tienden a coincidir espacialmente (Morales Lamberti, 2008: $6)$.

En el presente trabajo se estudiarán las siguientes aristas: a) se realiza un análisis del reconocimiento del derecho al ambiente sano como derecho humano que materializa la posibilidad de otros derechos humanos y refuerza la inevitable interconexión entre el ambiente y los derechos humanos desde una dimensión social (apartado II), en virtud de una interpretación integrada del complejo engranaje de fuentes enriquecido a la luz de los estándares del Sistema Interamericano de Derechos Humanos (SIDH) (apartado III). b) Se aborda la obligación imperativa que el daño ambiental generará prioritariamente la obligación de recomponer con especial referencia a la problemática de los PA (apartado IV), analizando en dicho marco el derecho de reparación integral y garantía de no repetición (apartado V) como medidas para abordar las inequidades en la distribución de las cargas y costos socio-ambientales de una contaminación histórica, que es arrastrada hacia tiempos presentes y se manifiesta como un potencial problema para las generaciones futuras.

\section{Interrelación entre los derechos humanos y el ambiente. Dimensiones de análisis}

"El derecho a un ambiente sano brinda un cimiento o base a la hora de enfrentar los problemas ambientales, desde un punto de vista tanto formal como de fondo" (Morales Lamberti: 2015: 142), para alcanzar niveles óptimos de protección.

Los derechos humanos se basan en el respeto de atributos humanos fundamentales, inherentes y naturales a la condición de persona humana - vida, salud, calidad de vida digna- y su realización y posibilidad de real concreción depende indefectiblemente de la existencia de un medio ambiente saludable que permita el desarrollo de esos atributos, sin lo cual serían de difícil e imposible realización y disfrute de otros derechos (Pezzano, Doroni, 2017) ${ }^{5}$.

\footnotetext{
${ }^{3}$ Esta consagración del derecho a un ambiente sano no es más que el reconocimiento de un derecho preexistente, es una condición previa, un prius y prerrequisito para la realización y disfrute de otros derechos humanos. Cfr. Sticca, M. A. (2013). Algunas reflexiones acerca del derecho al medio ambiente sano como derecho humano". En REY CARO, E. J. (Coord.). El Derecho Internacional Público como norma de conducta de los Estados. Córdoba: Gráfica Trejo.

${ }^{4}$ En adelante PA (pasivo ambiental).

${ }^{5}$ Derecho a un medio ambiente sano en la medida que permita el efectivo disfrute de otros derechos reconocidos a la persona humana, tal como lo señala Kiss (1987).
} 
Esta consagración del derecho a un ambiente sano no es más que el reconocimiento de un derecho preexistente, es una condición previa para el disfrute de los derechos humanos, es un prius, base y prerrequisito para la realización de los otros derechos humanos (Sticca, 2013: 338).

"El medio ambiente adecuado precede lógicamente al propio derecho: sin medio ambiente adecuado no hay vida humana, ni sociedad, ni Derecho" (Rota, 1998: 58).

"En la actualidad es difícil negar la categorización del derecho al medio ambiente sano como un derecho humano básico y esencial, en tanto su ejercicio apareja a su vez el goce y disfrute de los restantes derechos de los individuos" (Doroni, 2017). "Existe una relación innegable entre la protección del medio ambiente y la realización de otros derechos humanos" (Corte IDH, 2009) ${ }^{67}$.

\begin{abstract}
Los derechos humanos y el medio ambiente se relacionan entre sí de forma explícita e implícita, contribuyendo de manera importante al disfrute de los derechos humanos a un medio ambiente saludable. Varios problemas ambientales han buscado expresión en el lenguaje de los derechos humanos (cambio climático, discriminación ambiental, refugiados ambientales, daños transfronterizos, etc.), lo cual no resulta sorprendente y es incluso inevitable, por cuanto los derechos humanos y la protección de medio ambiente son inherentemente interdependientes para el derecho a la vida y salud (Morales Lamberti, 2009: 410).
\end{abstract}

El punto de convergencia e irrupción del derecho al medio ambiente se traduce, por un lado, en la expresión clásica e individualista del derecho a un ambiente sano como derecho humano natural e individual, ínsito a la condición de ser humano pero, por otro lado, implica también un derecho de indudable e innegable dimensión social (emplazamiento social del derecho) y colectiva (la defensa de los derechos humanos responde a un interés público y en este caso con una vocación colectiva): el campo social es el ámbito característicos de los conflictos ambientales, éstos no ocurren en vacíos sociales. "Entre la esfera pública y la privada hay una esfera social donde ubicamos a los bienes colectivos, lo cual instaura una regla de precedencia lógica en el caso de conflictos en bienes colectivos e individuales" (Lorenzetti, 2008: 12).

La dimensión colectiva, social, es consustancial al derecho ambiental y amplia los derechos jurídicos tutelados. Este es un cambio importantísimo en la cultura de los derechos humanos, a través de la institucionalización del paradigma ambiental que consagra una nueva relación que rompe con la lógica clásica de la supremacía de lo individual, reconduciendo la flecha de lo colectivo a lo individual" (Doroni, 2017: 113).

y que "se basa en una idea de interacción compleja, que toma en cuenta los efectos individuales y colectivos, presentes y futuros de la acción humana (derechos de cuarta generación o generaciones futuras) y que representa para los individuos un sistema donde predominan los deberes y límites a los derechos en razón de la protección que demanda el bien colectivo" (Lorenzetti, 2008: 11).

"La Constitución Nacional tutela al ambiente de modo claro y contundente y esta Corte Suprema ha desarrollado esa cláusula de un modo que permite admitir la existencia de un componente ambiental del estado de derecho. Por esta razón, cabe señalar que la efectividad que se reclama para todos los derechos fundamentales, también debe ser predicada respecto de los de incidencia colectiva y en particular del ambiente" 8 .

\footnotetext{
${ }^{6}$ Corte IDH: Caso Kawas Fernández vs. Honduras, sentencia de 3 de abril de 2009 (Fondo, Reparaciones y Costas. Serie C No. 196. párr. 148.). El derecho a un ambiente sano es una "condición" para el goce de otros derechos: varios derechos de rango fundamental requieren, como una precondición necesaria para su ejercicio, una calidad ambiental mínima, y se ven afectados en forma profunda por la degradación de los recursos naturales.

${ }^{7}$ Afirmado también por las Naciones Unidas, al adoptar la Agenda 2030 para el Desarrollo Sostenible, la Asamblea General reconoció que el alcance de los derechos humanos de todas las personas depende de la consecución de las tres dimensiones del desarrollo sostenible: la económica, social y ambiental. Cfr. Asamblea General de las Naciones Unidas, Resolución 70/1, titulada "Transformar nuestro mundo: la Agenda 2030 para el Desarrollo Sostenible", 25 de septiembre de 2015, Doc. ONU A/RES/70/1, preámbulo y párrs. 3, 8, 9, 10, 33, 35 y 67.

${ }^{8}$ CSJN, "Asociación Argentina de Abogados Ambientalistas de la Patagonia e/ Santa Cruz, Provincia de y otros/ amparo ambiental", Sentencia de fecha 24 de abril de 2016, CSJ 5258/2014.
} 
En el ámbito del medio ambiente existe un papel creciente de las Administraciones públicas, que constituye un campo de ensayo de técnicas e instrumentos jurídicos nuevos. La Administración sirve con objetividad los intereses generales. En materia de medio ambiente existe una no desdeñable peculiaridad. Ese servicio objetivo, que es uno de los pilares de nuestro Estado social, tiene como destinatarios a las generaciones presentes y futuras (Jordano Fraga, 2007: 102).

\section{Integración e interdependencia en el sistema de fuentes}

Con inusitada transcendencia para el derecho ambiental el Código Civil y Comercial integra una "comunidad de principios entre la Constitución", el derecho privado y el derecho público (Fundamentos del Anteproyecto) ${ }^{9}$. Los tratados de derechos humanos deben ser tenidos como fuente ${ }^{10}$, y juegan un rol clave en la labor de interpretación y aplicación de la norma-según lo estipulado por el artículo segundo ${ }^{11}$ - adquiriendo especial relevancia (de modo explícito) el régimen de derechos humanos, al brindar estándares de integración hermenéutica en el mandato de un análisis completo y coherente de todo el ordenamiento.

Se observa una clara comunicación y relación entre el derecho ambiental y el derecho general, lo que invita a una relectura de los derechos individuales a la luz de los derechos de incidencia colectiva ${ }^{12}$, a través de una fuente de coordinación-compatibilización ("conformidad en el ejercicio de los derechos individuales con los derechos de incidencia colectiva") establecida en el artículo $240^{13}$ y otra de subordinación (límite al ejercicio abusivo del derecho individuales cuando pueda afectar al medio ambiente) en el artículo 14 (Morales Lamberti,2015: 140).Claramente se observa un criterio de compatibilización del derecho individual para con los derechos de incidencia colectiva (en lo que aquí respecta el medio ambiente). En tercer lugar, encontramos una fuente de internalización de la normativa de presupuestos mínimos ${ }^{14}$ como así también de aquellas normas locales- nacionales, provinciales y municipales- complementarias ${ }^{15}$, lo que importa la necesidad de un diálogo de fuentes (Morales Lamberti, 2015: 140).

El complejo engranajes de fuentes requiere una consonancia del sistema de derechos y garantías reconocidas a nivel constitucional (control de constitucionalidad) en un único bloque de constitucionalidad que se integra con el sistema de derechos humanos (control de convencionalidad) ${ }^{16}$,

\footnotetext{
${ }^{9}$ Se establece una constitucionalización del derecho privado, al internalizar los tratados en general, en particular los de derechos humanos y los derechos reconocidos en todo el bloque de constitucionalidad. Puede afirmarse que existe una reconstrucción de la coherencia del sistema de derechos humanos con el derecho privado. Cfr. Fundamentos del Anteproyecto de Código Civil y Comercial, Comisión Redactora creada por decreto $N^{\circ}$ 191/2011.

${ }^{10}$ Art. 1: Fuentes y aplicación. Los casos que este Código rige deben ser resueltos según las leyes que resulten aplicables, conforme con la Constitución Nacional y los tratados de derechos humanos en los que la República sea parte. A tal efecto, se tendrá en cuenta la finalidad de la norma. Los usos, prácticas y costumbres son vinculantes cuando las leyes o los interesados se refieren a ellos o en situaciones no regladas legalmente, siempre que no sean contrarios a derecho.

11 "La ley debe ser interpretada teniendo en cuenta sus palabras, sus finalidades, las leyes análogas, las disposiciones que surgen de los tratados sobre derechos humanos, los principios y los valores jurídicos, de modo coherente con todo el ordenamiento".

${ }^{12}$ Es un código de los derechos individuales y colectivos. En su mayoría, los códigos del derecho privado comparado regulan sólo los derechos individuales. El Anteproyecto da una importancia relevante a los derechos de incidencia colectiva, en consonancia con la Constitución Nacional. Esto tiene un impacto significativo en el modo de relacionamiento con los recursos naturales. Fundamentos del Anteproyecto de Código Civil y Comercial, Comisión Redactora creada por decreto $\mathrm{N}^{\circ} 191 / 2011$.

13 "El ejercicio de los derechos individuales debe ser compatible con los derechos de incidencia colectiva. Debe conformarse a las normas del derecho administrativo nacional y local dictadas en el interés público y no debe afectar el funcionamiento ni la sustentabilidad de los ecosistemas de la flora, la fauna, la biodiversidad, el agua, los valores culturales, el paisaje, entre otros, según los criterios previstos en la ley especial".

${ }^{14}$ EL artículo 241 expresa que cualquiera sea la jurisdicción en que se ejerzan los derechos, debe respetarse la normativa sobre presupuestos mínimos que resulte aplicable.

${ }^{15}$ Debe conformarse a las normas del derecho administrativo nacional y local dictadas en el interés público (art. 240).

${ }^{16}$ Para efectos de determinar la compatibilidad con la CADH, no sólo se debe tomar en consideración el tratado, sino que también la jurisprudencia de la Corte IDH y los demás tratados interamericanos de los cuales el Estado sea parte. En esta tarea, el Poder Judicial debe tener en cuenta no solamente el tratado, sino también la interpretación que del mismo ha hecho la Corte Interamericana, intérprete última de la Convención Americana. Conforme Corte IDH. Caso Almonacid Arellano y
} 
lo que propicia una relectura de las interacciones entre los derechos humanos y el medio ambiente, enriquecido y fortalecido a través del SIDH (Morales Lamberti, 2015: 141).

En este sentido,

la norma convencional que deben aplicar los estados es el resultado de la interpretación de las disposiciones del Pacto de San José (y sus protocolos adicionales, así como otros instrumentos internacionales). Las interpretaciones que realiza la Corte IDH se proyectan hacia dos dimensiones: (i) en lograr su eficacia en el caso particular con efectos subjetivos, y (ii) en establecer la eficacia general con efectos de norma interpretada ${ }^{17}$.

En resumen, podemos determinar los siguientes criterios para el alcance, ejercicio y compatibilidad de los derechos (en su dimensión individual y colectiva): a) adecuación a la Constitución Nacional y a las disposiciones y estándares que surgen de los tratados internacionales de derechos humanos; b) conformidad con el SIDH; c) compatibilidad y coordinación con los derechos de incidencia colectiva un ejercicio no abusivo-; d) conformidad con el ordenamiento jurídico que debe ser interpretado de manera congruente, lo que implica tener en cuenta las normas de fondo y forma contenidas en nuestra Ley General del Ambiente (LGA) y demás normativa de protección sectorial y con las normas locales complementaria - que deben ser congruentes y acordes a los presupuestos mínimos- (orden público ambiental) (Morales Lamberti,2015: 141).

\title{
IV. Mandato imperativo de recomponer el daño ambiental. El problema de los pasivos ambientales
}

El sistema de responsabilidad tiene como principal objetivo la prevención y anticipación de los daños ${ }^{18}$, ocurrido el daño ambiental colectivo se pretende la cesación del daño y evitación de su agravamiento. Seguidamente,

\begin{abstract}
"las medidas de reparación y/o restauración tienen por objeto reponer uno o más de los componentes o elementos del medio ambiente y/o servicios ambientales afectados a una calidad similar a la que tenían con anterioridad o, al menos, restablecer sus propiedades y condiciones básicas" (Morales Lamberti, 2008: 185),
\end{abstract}

operando la indemnización sustitutiva como la última ratio del sistema ${ }^{1920}$.

otros Vs. Chile.Excepciones Preliminares, Fondo, Reparaciones y Costas. Sentencia de 26 de septiembre de 2006. Serie C No. 154, párr. 124; Cfr.Corte IDH. Caso La Cantuta Vs. Perú. Fondo, Reparaciones y Costas. Sentencia de 29 de noviembre de 2006. Serie C No. 162, párr. 173.

${ }^{17}$ Voto concurrente razonado del juez Ferrer Mac-Gregor a la Resolución de la Corte Interamericana de Derechos Humanos de 20 de marzo de 2013. (Caso Gelman Vs. Uruguay. Supervisión de Cumplimiento de Sentencia).Ver "Control de Convencionalidad". Cuadernillo de Jurisprudencia de la CIDH N7, 16-17. Caso Gelman Vs. Uruguay. Supervisión de Cumplimiento de Sentencia. Resolución de la Corte Interamericana de Derechos Humanos de 20 de marzo de 2013 , párr. 67-69.

${ }^{18}$ Receptada esta ampliación de las funciones de la responsabilidad, en el art. 1708: Las disposiciones de este Título son aplicables a la prevención del daño y a su reparación”. En los fundamentos del nuevo Código Civil y Comercial se dice que: "en los derechos de incidencia colectiva, surge con claridad que la prevención es prioritaria y precede a la reparación, sobre todo cuando se trata de bienes que no se pueden recomponer fácilmente (...)".

${ }^{19}$ En ese sentido Pizarro manifiesta que "La finalidad perseguida es prevenir los atentados ambientales y, producidos éstos, exteriorizar una reacción vigorosa del sistema en todos los planos: penal, resarcitorio y administrativo. Urge implementar técnicas adecuadas para desmantelar los efectos de los ilícitos ambientales, que actúen como instrumentos eficaces de prevención, neutralización, reparación y punición del daño ambiental”. Cfr. PIZARRO, Ramón Daniel. "Responsabilidad civil por daño ambiental", Tutela Jurídica del Medio Ambiente, Ediciones de la Academia Nacional de Derecho y Ciencias Sociales de Córdoba, Volumen XLV, año 2008, ISBN 978-987-1123-48-3, pág. 156.

${ }^{20}$ Respecto a esto la CSJN ha manifestado que "en la tutela del bien colectivo configurado por el ambiente, tiene una prioridad absoluta la prevención del daño futuro, en segundo lugar debe perseguirse la recomposición de la polución ambiental ya causada y finalmente, para el supuesto de daños irreversibles, se tratará del resarcimiento"(...) para la tutela de un bien colectivo, el que por su naturaleza jurídica, es de uso común, indivisible y está tutelado de una manera no disponible por las partes, primero corresponde la prevención, luego la recomposición y, en ausencia de toda posibilidad, se 
No se trata de una reparación meramente pecuniaria, sino una reparación en especie, que implica restablecer las cosas al estado en que se encontraban antes de la producción del hecho dañoso. Esta primitiva obligación de recomponer el daño ambiental tiene fuente constitucional (art. 41), el mandato imperativo determina que "el daño ambiental generará prioritariamente la obligación de recomponer, según lo establezca la ley" (artículo 41 de la Constitución Nacional).

"Conforme nuestro régimen vigente, daño ambiental, equivale a daño ambiental de incidencia colectiva (lesión de intereses y derechos de incidencia colectiva en términos constitucionales)" (Morales Lamberti,2008:12). "Nuestro régimen de responsabilidad ambiental promueve la evitación de nuevos y futuros PA y se constituye en un instrumento eficaz para la reparación de daños ambientales colectivos" (Morales Lamberti,2008:11). Pero no comprendería en un sentido estricto, desde un punto de vista técnico-jurídico, la responsabilidad por remediación de PA (preexistente y residual) (Morales Lamberti,2008:11), surgiendo la problemática de ¿quién debe cargar con los costes (sociales y ambientales) de la contaminación del pasado?

El conflicto que plantean los PA es su inserción en nuestro sistema normativo de responsabilidad ambiental, de esto se desprende el siguiente interrogante: ¿cómo abordar técnica y jurídicamente a los PA en el marco normativo de atribución de responsabilidad? Plausiblemente del mandato de la LGA surge a través del principio de responsabilidad que "el generador de efectos degradantes del ambiente, actuales o futuros, es responsable de los costos de las acciones preventivas y correctivas de recomposición (...)" (artículo 4, Ley 25.675), pero no abarca aquellos sitios con contaminación histórica, cuyos efectos se manifiestan en el presente pero su causa fuente de gestación es pretérita.

Sin embargo, la primera cuestión a dilucidar es ¿qué entendemos por PA? Antes que nada hay que destacar que un PA no es necesariamente daño ambiental; dicho de otro modo, no se sigue que un pasivo ambiental se exteriorice en un daño. Esto encierra un problema conceptual porque si puede que no haya daño, ¿por qué se lo define constantemente (en la doctrina y en la legislación) como una especie de daño o conjunto de daños ${ }^{21}$

Esto se debe a que es necesario identificar y diferenciar la categoría de PA configurado y PA contingente de acuerdo al grado de configuración (conforme al grado de certeza de su ocurrencia). En el primer caso al PA sí se lo puede categorizar como una especie o categoría de daño ambiental especial, que generará prioritariamente su recomposición, restauración o eventualmente su compensación (Morales Lamberti,2008:8). En el segundo caso, el PA refiere a la probabilidad de que un daño ocurra (en términos potenciales), pero no se conoce a ciencia cierta si eso ocurrirá ${ }^{22}$.

dará lugar al resarcimiento (art. 28, ley 25675)”. CSJN, autos Mendoza, Beatriz Silvia y otros c/ Estado Nacional y otros s/ daños y perjuicios (daños derivados de la contaminación ambiental del Río Matanza - Riachuelo) M. 1569. XL; ORI Pronunciamiento de fecha 20/06/2006.

${ }^{21}$ A modo de ejemplo dentro del sistema encontramos algunas normativas provinciales que abordan el tema. La Ley $\mathrm{N}^{\mathrm{o}}$ 14.343 - Ley de Regulación de Pasivos Ambientales de la Provincia de Buenos Aires- brinda una definición legal de pasivo ambiental “... se entenderá por pasivo ambiental al conjunto de los daños ambientales, en términos de contaminación del agua, del suelo, del aire, del deterioro de los recursos naturales y de los ecosistemas, producidos por cualquier tipo de actividad pública o privada, durante su funcionamiento ordinario o por hechos imprevistos a lo largo de su historia, que constituyan un riesgo permanente y/o potencial para la salud de la población, el ecosistema circundante y la propiedad, y que haya sido abandonado por el responsable". En un sentido concordante encontramos la Ley 10208 - Ley de Política Ambiental de la Provincia de Córdoba- que en su artículo 89 estipula que "se entiende por pasivo ambiental al conjunto de impactos ambientales negativos e irreversibles que impliquen el deterioro de los recursos naturales y de los ecosistemas, producidos por cualquier tipo de actividad pública o privada, durante su funcionamiento ordinario o por hechos imprevistos a lo largo de su historia, que constituyan un riesgo permanente o potencial para la salud humana, el ecosistema o la propiedad".

${ }^{22}$ Se asocia a la idea de riesgo, por ejemplo un depósito de residuos peligrosos es un potencial riesgo de daño ambiental, ya que si no es debidamente tratado, si no se realiza la correcta disposición, operación de cierre, pos cierre o si permanecen acumulados en estado de abandono, esos hechos generan un pasivo ambiental, que no implica, necesariamente, que el daño ambiental colectivo -en los términos del art. 27 de la LGA- esté materializado o configurado. 
"El término PA tiene orígenes empresariales" (Russi y Martínez-Alier, 2002:108). "El "pasivo" es una de las dos partidas fundamentales en el balance de una compañía o en la contabilidad departida doble. En inglés es liability and assets; en español, pasivos y activos" (Cardoso, 2016: 94).

En ese sentido, el PA se plasma en un asiento contable (existencia, reconocimiento del PA), materializado como una obligación de incurrir en un gasto (erogación). Puede que se conozca el alcance del PA (costo cierto), o que sea una posible obligación (contingente), ya que el cumplimiento o exigencia puede o no ocurrir; el PA está identificado en uno y otro caso (sea configurado o contingente). La diferencia radica en la probabilidad de que la erogación deba efectivamente efectuarse, con grado de exactitud al tratarse de un PA configurado o con un halo de incertidumbre al tratarse de un PA contingente ${ }^{23}$, constituyendo una obligación posible "cuya existencia puede ser consecuencia, con cierto grado de incertidumbre, de un suceso futuro o no ser susceptible de cuantificación en un determinado momento" (Morales Lamberti, 2008: 119).

En términos jurídicos se podría decir que "un PA es una obligación legal de pagar una suma de dinero o incurrir en un gasto, por lo que subyace la idea de que un pasivo supone necesariamente la existencia de un responsable" (UPME, 2002: 2). "Es una obligación -una deuda social, económica y ambientalque se deriva de la mitigación, recomposición, remediación por un impacto no mitigado" (Morales Lamberti, 2008: 303) o por el potencial riesgo de que un daño ambiental se configure, que responde a un legado de contaminación histórica ${ }^{24}$.

La gestión de pasivos ambientales genera un problema intergeneracional, porque fácticamente nos encontramos ante sitios contaminados en un estado de deterioro y degradación, generalmente en estado de abandono o inactivos, sin ningún tipo de medida de mitigación y remediación. Dicha situación constituye un riego potencial y permanente, que configura la probabilidad de que un daño ambiental se materialice. "Su configuración exige siempre como obligación ambiental y social su saneamiento" (Morales Lamberti, 2008: 303), lo que implicará la obligación de incurrir en un gasto (sea de prevención, gestión, remediación del sitio contaminado).

Se debe incorporar al análisis el factor temporal porque es una contaminación que se comenzó a originar en el pasado pero sus efectos se trasladan a la actualidad; si bien se empezó a gestar en un momento anterior tiene actualidad al no encontrarse debidamente (en términos técnicos y jurídicos) remediado. Por lo tanto, encontramos una "conjunción de momentos temporales distintos": por un lado, el momento de la gestación del PA y por otro el momento en que se comienzan a evidenciar sus posibles efectos, lo que plantea una proyección temporal: es un hecho que se origina en una causa de gestación pretérita pero cuyos efectos están presentes y latentes, no solo en la actualidad sino con la posibilidad de seguir arrastrando ese legado de contaminación hacia el futuro.

Si no es posible identificar al causante del PA o si el mismo resulta insolvente, el Estado debe asumir una posición en torno a la problemática, es por eso que se genera una responsabilidad subsidiaria del Estado, quien termina absorbiendo los PA, para evitar seguir traspasándolos generacionalmente. Los PA constituyen un riesgo fiscal, ya que esos costos no internalizado por el causante se convierten en pasivos fiscales del presente (Morales Lamberti: 2008, 228).

Se genera un conflicto temporo-espacial por las propias condiciones que presentan los PA, ya sea por materializase o por representar un riesgo potencial y permanente de DA, que lo sufrieron en el pasado, se sufre en el presente y se puede trasladar hacia el futuro, lo que conlleva la necesidad de una visión

\footnotetext{
${ }^{23}$ El término surge del concepto contable de pasivo, que engloba todas las obligaciones que asume una entidad (persona física o jurídica con obligación de llevar libros contables). A este término se le añade el adjetivo contingente, que a su vez procede de contingencia, en el sentido de que dicha obligación no es segura, pero puede producirse en un futuro previsible. Conforme Morales Lamberti, Alicia (2008). Pág. 119.

${ }^{24}$ El ministerio de ambiente de Colombia los define como "impactos ambientales negativos, ubicados y delimitados geográficamente, que no fueron oportuna o adecuadamente mitigados, compensados, corregidos o recuperados; causados por actividades antrópicas y que pueden generar un riesgo a la salud humana o al ambiente" (Minambiente-Innova, 2015, p. 28).
} 
diacrónica por los efectos intergeneracionales que se evidencian. Indubitablemente la cuestión es compleja: la afección recae en derechos de incidencia colectiva, "de predominante base social, que requiere inexorablemente una mirada hacia el pasado que se arrastra hacia el futuro". "Este concepto de tiempo y espacio ayuda a entender la herencia del pasado y las relaciones o interconexiones con el futuro. Estamos esencialmente vinculados a otras generaciones, pasadas y futuras" (George, 2012: 33).

\title{
V. Reparación Integral y Garantía de no repetición. ¿Cómo se enriquece nuestro sistema con los estándares de protección del SIDH?
}

Como se puede observar la reparación es un derecho con estatus constitucional ${ }^{25}$ y requiere ser releído (en el engranaje de nuestro sistema de fuentes) con un contenido predominante social y colectivo $^{26}$. La propia $\operatorname{CSJN}^{27}$ precisó el contenido del derecho de reparación: "todo aquel que cause daño ambiental es responsable de restablecer las cosas al estado anterior a su producción (art. 41 de la Constitución Nacional, art. 27 de la ley 25.675)".

De allí que la máxima reparación integral se reafirma, refuerza e enriquece en la interconexión del medio ambiente y los derechos humanos, por medio de una interpretación hermenéutica y progresiva: "la interrelación entre los derechos humanos y el medio ambiente, y los derechos humanos afectados por causa de la degradación del medio ambiente, incluyendo el derecho a un medio ambiente sano" (Corte Interamericana de Derechos Humanos) ${ }^{28}$.

\begin{abstract}
El derecho humano a un medio ambiente sano se ha entendido como un derecho con connotaciones tanto individuales como colectivas. En su dimensión colectiva, el derecho a un medio ambiente sano constituye un interés universal, que se debe tanto a las generaciones presentes y futuras. Ahora bien, el derecho al medio ambiente sano también tiene una dimensión individual, en la medida en que su vulneración puede tener repercusiones directas o indirectas sobre las personas debido a su conexidad con otros derechos, tales como el derecho a la salud, la integridad personal o la vida, entre otros (Corte Interamericana de Derechos Humanos) $)^{29}$.
\end{abstract}

"La propia CIDH ha reconocido la necesidad de tutelar los derechos económicos, sociales, culturales y ambientales (DESCA)" (Morales Lamberti, 2015: 146) ${ }^{30}$, no sólo en su dimensión individual sino

\footnotetext{
${ }^{25}$ Como destaca el Dr. de Lázzari, la Corte Nacional brindó sustento constitucional al derecho a la reparación en los fallos "Santa Coloma” (Fallos: 308:1160), “Gunther" (Fallos: 308:1118) y "Luján” (Fallos: 308:1109) del 5/08/86, que extrajo del "alterum non laedere" del art. 19 de la C.N. (conceptos "entrañalablemente unidos" según la Corte). No es el único fundamento. También, como ha señalado Sagüés ("Notas sobre el derecho constitucional a la reparación", E.D. del 2/06/03) se lo ha considerado derecho inferido de los arts. 14 y 17 de la C.N. (C.S.J.N., "Motor Once", E.D. 134-411), derivado del fin de afianzar lajusticia contenido en el preámbulo ("Santa Coloma"), o como derecho implícito o no enumerado del art.33 de la C.N.. Y, a partir de la reforma constitucional de 1994, inferido de disposiciones de tratados de derechos humanos, como el art. 10 de la C.A.D.H. que reconoce el derecho a la reparación del que ha sido condenado penalmente y luego absuelto en un juicio de revisión, del art. 13 que reconoce la reparación de daños a la reputación de las personas causados por la prensa, o el art. 63 de la misma convención que establece que la Corte Interamericana puede disponer que se reparen las consecuencias de la medida considerada violatoria de los derechos por ella tutelados. Cfr. Expte. Nro. 110.669- Sala I Cámara de Apelación en lo Civil y Comercial del Departamento Judicial Mercedes de la Pcia. de Buenos Aires- Autos: Acevedo, Hilda y ots. c/ Hosp. Municip. M. y L. De la Vega y otros. s/ Daños y perjuicios. Sentencia del 12 de Junio de 2007.

${ }^{26}$ En este sentido, a su vez corresponde justipreciar las consecuencias que afecten a la víctima, tanto desde el punto de vista individual como desde el social, lo que le confiere un marco de valoración más amplio. Cfr. CSJN Ramírez, Juan Carlos c/ Entidad Nacional Yaciretá. Sentencia de fecha 11 de julio de 2007.

${ }^{27}$ Cruz, Felipa y Otros c/ Minera Alumbrera Limited y otro s/ Sumarísimo de fecha 23 de febrero de 2016.

${ }^{28}$ CHID, Opinión Consultiva OC-23/17, párrf.46, de 15 de noviembre de 2017, solicitada por la República de ColombiaMedio ambiente y derechos humanos

${ }^{29}$ CHID, Opinión Consultiva OC-23/17, párrf.59, de 15 de noviembre de 2017, solicitada por la República de ColombiaMedio ambiente y derechos humanos.

${ }^{30}$ El preámbulo del Protocolo Adicional a la Convención Americana sobre Derechos Humanos en materia de Derechos Económicos, Sociales y Culturales (en adelante "Protocolo de San Salvador"), resalta la estrecha relación entre la vigencia de los derechos económicos, sociales y culturales -que incluye el derecho a un medio ambiente sano - y la de los derechos civiles y políticos, e indica que las diferentes categorías de derechos constituyen un todo indisoluble que encuentra su base en el reconocimiento de la dignidad de la persona humana, por lo cual exigen una tutela y promoción permanente con el
} 
también en su dimensión colectiva, redireccionando las pautas y estándares mínimos en materia de derechos humanos y el alcance (ampliación) de las reparaciones ante reclamos de tinte colectivo.

La especial naturaleza del derecho a un ambiente sano encuentra su fuente en los derechos de incidencia colectiva o en aquellos en los cuales prevalecen aspectos ligados a intereses colectivos o grupales" (...) "Son procesos en que el bien jurídico ambiental comprometido es colectivo, supraindividual, indivisible, impersonal y no fraccionable en cuotas adjudicables a cada uno de sus titulares en el sentido concordemente definido por esta Corte (...). Se trata, pues, únicamente de aquellos casos en que los derechos cuya tutela se persigue corresponden a un bien que pertenece a la esfera social y transindividual $^{31}$.

Esto "pone en evidencia que la línea directriz hermenéutica en estos casos se centra en la protección del medio ambiente como bien social de disfrute general e intergeneracional (...) este tipo de cuestiones deben examinarse a la luz del principio de equidad intergeneracional, en cuanto dispone que los responsables de la protección ambiental deberán velar por el uso y goce apropiado del ambiente por parte de las generaciones presentes y futuras ${ }^{32}$.

La reparación ha de ser integral, plena y eficaz ${ }^{33}$ lo que implica que debe (como ideal) eliminar los efectos del hecho y restablecer a la situación anterior, tratando de borrar o hacer desaparecer los efectos que la acción dañosa ha generado ${ }^{34}$. En ese sentido, la CIDH ha manifestado que "la reparación, como la palabra lo indica, está dada por las medidas que tienden a hacer desaparecer los efectos de la violación cometida" 35 . La CSJN ha manifestado que se deben realizar "todas las acciones que resulten necesarias para la recomposición integral de los daños colectivos ambientales causados" $" 36$.

La jurisprudencia internacional, y en particular de la Corte IDH, ha establecido reiteradamente que "la sentencia constituye per se una forma de reparación" 37 . Los estándares fijados en SIDH han delineado la obligación de reparación integral y garantía de no repetición estipulada en el art. 63 de la CADH.

La CIDH ha indicado que "toda violación de una obligación internacional que haya producido daño comporta el deber de repararlo adecuadamente y que esa disposición recoge una norma consuetudinaria que constituye uno de los principios fundamentales del Derecho Internacional contemporáneo sobre responsabilidad de un Estado. La reparación del daño requiere, siempre que sea posible, la plena restitución, que consiste en el restablecimiento de la situación anterior.

De no ser esto factible, como ocurre en la mayoría de los casos de violaciones a derechos humanos, el Tribunal determinará medidas para garantizar los derechos conculcados y reparar las consecuencias que las infracciones produjeron. Por tanto, la Corte ha considerado la necesidad de otorgar diversas medidas de reparación, a fin de resarcir los daños de manera integral, por lo que además de las compensaciones

objeto de lograr su vigencia plena, sin que jamás pueda justificarse la violación de unos en aras de la realización de otros. (CHID, Opinión Consultiva OC-23/17, de 15 de noviembre de 2017, solicitada por la República de Colombia- Medio ambiente y derechos humanos).

${ }^{31}$ CSJN: Asociación de Superficiarios de la Patagonia c/ Y.P.F. S.A. y otros s/ daño ambiental. Sentencia de fecha 29 de agosto de 2006.

${ }^{32}$ Ibídem.

${ }^{33} \mathrm{El} \mathrm{CCyC}$ establece en su art.1740que la reparación del daño debe ser plena. Consiste en la restitución de la situación del damnificado al estado anterior al hecho dañoso (...).

${ }^{34}$ Incluso en daños inconmensurables como lo es el daño al medio ambiente lo que se pretende es conmensurarlos, cumpliendo una función compensatoria.

35 Cfr. Caso Velásquez Rodríguez Vs. Honduras. Reparaciones y Costas, párr. 25, y Caso López Lone y otros Vs. Honduras. Excepción Preliminar, Fondo, Reparaciones y Costas. Sentencia de 05 de octubre de 2015. Serie C No. 302, párr. 286. Caso Garrido y Baigorria Vs. Argentina Sentencia de 27 de agosto de 1998 (Reparaciones Y Costas), párr. 41.

${ }^{36}$ Asociación de Superficiarios de la Patagonia c/ Y.P.F. S.A. y otros s/ daño ambiental. Sentencia de fecha 29/08/2006

${ }^{37}$ Cfr. Caso Neira Alegría y otros Vs. Perú. Reparaciones y Costas, párr. 56, y aso de personas dominicanas y haitianas expulsadas Vs. República Dominicana. Excepciones Preliminares, Fondo, Reparaciones y Costas. Sentencia de 28 de agosto de 2014. Serie C No. 282, párr. 448. Caso de los Pueblos Indígenas Kuna de Madungandí y Emberá de Bayano y sus miembros vs. Panamá. Sentencia de 14 de octubre de 2014(Excepciones Preliminares, Fondo, Reparaciones y Costas), párr. 206. Pueblo indígena Kichwa de Sarayaku vs. Ecuador sentencia de 27 de junio de 2012 (Fondo y Reparaciones), párr. 285. Caso del Pueblo Saramaka vs. Surinam. Sentenciadel 28 de noviembre de 2007 (Excepciones Preliminares, Fondo, Reparaciones y Costas), párr. 195. Caso Claude Reyes y otros Vs. Chile Sentencia de 19 de septiembre de 2006 (Fondo, Reparaciones y Costas), párr. 156. 
pecuniarias, las medidas de restitución, satisfacción y garantías de no repetición tienen especial relevancia por los daños ocasionados ${ }^{38}$.

La remediación de un PA tiene efectos en el presente y persigue una finalidad generacional: por un lado, se determina la atribución de responsabilidades derivadas de conductas adoptadas en el pasado y, por otro lado, el objeto de la decisión se orienta hacia el futuro, para evitar el traspaso de legados de contaminación a las generaciones futuras y apreciar (ponderadamente) las alteraciones que puedan producirse en el ambiente y en la sociedad (actual y futura). De allí que toda medida que se adopte debe tener indefectiblemente en cuenta esta temporalidad intergeneracional.

En este sentido, la garantía de no repetición, pretende que violaciones similares no vuelvan a ocurrir. Llevan ínsitamente una "vocación transformadora de dicha situación, de tal forma que las mismas tengan un efecto no sólo restitutivo" 39 (remediar la situación del pasado que se traslada a días de hoy) "sino también correctivo hacia el futuro" ${ }^{40}$. En propias palabras de la CIDH, "las garantías de no repetición adquieren una mayor relevancia como medida de reparación, a fin de que hechos similares no se vuelvan a repetir y contribuyan a la prevención"41.

De esto se sigue, que la garantía de no repetición indica un expreso mandato positivo al Estado (más allá de que se determine o no el causante del PA) de sanear el arrastre de un legado de contaminación y de actuar para evitar el agravamiento del PA (nueva acumulación) y nueva generación de PA -cese, paralización y evitación de los posibles efectos negativos que se pueden sobrevenir- ${ }^{42}$, lo que implica una mira generacional del problema, remediación de PA generados en el pasado con una proyección hacia el presente (evitando que el PA ocasiona efectivamente un daño) y futuro (desde un accionar preventivo y precautorio en la generación de nuevos PA).

\section{expresión}

Por último, corresponde analizar la fijación de una indemnización. La CIDH señaló que la

justa indemnización' utilizada en el artículo 63.1 de la Convención es 'compensatoria y no sancionatoria' y que el Derecho internacional desconoce la imposición de indemnizaciones 'ejemplarizantes o disuasivas'. Igualmente, expresó que el derecho internacional de los derechos humanos no tiene por objeto imponer penas a las personas culpables de sus violaciones, sino amparar a las víctimas y disponer la reparación de los daños que les hayan sido causados ${ }^{43}$.

La CSJN ha determinado "que resulta inconstitucional una indemnización que no fuera "justa", puesto que "indemnizar es [...] eximir de todo daño y perjuicio mediante un cabal resarcimiento", lo cual no se logra "si el daño o el perjuicio subsisten en cualquier medida" (...) En definitiva, negar una indemnización integral, justa y equitativa no se encontraría en armonía con uno de los principios

\footnotetext{
${ }^{38}$ Cfr. Caso Velásquez Rodríguez Vs. Honduras. Reparaciones y Costas, párr. 25 y Caso López Lone y otros Vs. Honduras. Excepción Preliminar, Fondo, Reparaciones y Costas. Sentencia de 05 de octubre de 2015. Serie C No. 302, párr. 286. Caso Castillo Páez Vs. Perú. Reparaciones y Costas, párr. 50, y Caso López Lone y otros Vs. honduras, párr. 286. comunidad garífuna triunfo de la cruz y sus miembros vs. honduras. Sentencia de 8 de octubre de 2015 (Fondo, Reparaciones y Costas), párr. 254-255. Pueblo Indígena Kichwa de Sarayaku vs. Ecuador. Sentencia de 27 de junio de 2012 (Fondo y Reparaciones), párr. 279-280. Caso Claude Reyes y otros Vs. Chile. Sentencia de 19 de septiembre de 2006 (Fondo, Reparaciones y Costas), párr. 150-151.

${ }^{39}$ Corte IDH, Atala Riffo y Niñas c. Chile, sentencia de fondo, reparaciones y costas. Sentencia del 24 de febrero de 2012 , párr.267.

${ }^{40}$ Ibídem.

${ }^{41}$ Caso Luna López vs. Honduras. Sentencia de 10 de octubre de 2013 (Fondo, Reparaciones y Costas), párr. 234. En igual sentido, Caso Claude Reyes y otros Vs. Chile. Sentencia de 19 de septiembre de 2006 (Fondo, Reparaciones y Costas), párr. 151: Es necesario añadir las medidas de carácter positivo que el Estado debe adoptar para asegurar que no se repitan hechos.

${ }^{42}$ Ciclo que se observa en el art. 1710 del CCyC: deber de prevención del daño. Toda persona tiene el deber, en cuanto de ella dependa, de: a) evitar causar un daño no justificado; b) adoptar, de buena fe y conforme a las circunstancias, las medidas razonables para evitar que se produzca un daño, o disminuir su magnitud; c) no agravar el daño, si ya se produjo.

${ }^{43}$ Caso Velásquez Rodríguez, Indemnización Compensatoria, supra 40, párr. 38 y Caso Godínez Cruz, Indemnización Compensatoria, supra 40, párr. Caso Fairén Garbi y Solís Corrales, Sentencia del 15 de marzo de 1989. Serie C No. 6, párr. 136. Caso Garrido y Baigorria Vs. Argentina Sentencia de 27 de agosto de 1998 (Reparaciones y Costas), párr. 44.
} 
señeros de nuestra Constitución Nacional y del derecho Internacional de los derechos humanos, como es el de la justicia social" 44 .

La gestión de los PA implica remediar, sanear, efectuar una correcta disposición final para alcanzar niveles tolerables en la capacidad de auto regeneración del ambiente afectado. Sin embargo, aún si ello fuere posible no podremos afirmar que se logró una recomposición integral ${ }^{45}$, sobre todo cuando estamos en presencia de efectos irreversibles. Incluso cuando la recomposición no resulte técnicamente factible se prevé la indemnización sustitutiva de carácter compensatorio, cuya determinación se torna sumamente complejo debido a que sería necesario conocer y fijar el valor o utilidad social y ambiental - para las generaciones actuales y futuras- del conjunto de los recursos y flujo de servicios ambientales46.

\section{Reflexiones Finales}

El análisis anterior ha procurado delinear la necesaria interacción entre los derechos humanos y el medio ambiente, enriquecido desde una dimensión social del derecho, a través de una interpretación integrativa y sistemática de nuestro sistema de fuentes, haciendo énfasis en la problemática de los PA, con referencias a la reparación integral y garantías de no repetición.

Se genera un conflicto temporo-espacial por las propias condiciones que presentan los PA, ya sea por materializase o por representar un riesgo potencial y permanente de daño ambiental, que lo sufrieron en el pasado, se sufre en el presente y se puede trasladar hacia el futuro, lo que conlleva la necesidad de una visión diacrónica por los efectos intergeneracionales que se evidencian.

Desde esta perspectiva, medidas de no repetición, garantizan hacia el futuro que esos hechos que lesionan, amenazan, restringen o alteren los derechos y garantías reconocidos no se repetirán. Es un modo de subsanar y compensar los errores hacia el pasado, como así también de evitar el agravamiento y nueva generación de PA - cese, paralización y evitación de los posibles efectos negativos que se pueden sobrevenir-. Lo que implica una mira generacional del problema: remediación de PA generados en el pasado con una proyección hacia el presente (evitando que el PA ocasiona efectivamente un daño) y futuro (desde un accionar preventivo y precautorio en la generación de nuevos PA).

Por otro lado, las medidas de remediación y/o recomposición integral pretenden brindar una solución al problema en un sentido dialógico pasado-presente-futuro, compensando una deuda social y ambiental que se arrastra de tiempos pretéritos, que perjudica por sobre todo a sectores vulnerables y desprotegidos, evitando que el PA devenga en un DAC con efectos presentes y futuros, lo que en última instancia implica un corte del traspaso del problema hacia las generaciones futuras (de generación en generación).

"Si se tiene presente que los derechos humanos se centran en las personas excluidas, marginadas o que se encuentran en una situación de riesgo" (Morales Lamberti, 2015: 161) y vulnerabilidad, la interacción entre los derechos humanos y el medio ambiente brinda nuevas herramientas y garantías para enfrentar este tipo de problemas intergeneracionales, enriquecido con una visión integral y

44 Ramírez, Juan Carlos c/ Entidad Nacional Yaciretá. Sentencia de fecha 11 de julio de 2007.

${ }^{45}$ Que implica tener en cuenta el estado de los recursos naturales y flujos de servicios ambientales desde que se produjo el daño hasta el momento en que la reparación aproxime al máximo a esos recursos y servicios a su estado original -teniendo en cuenta un nivel cuantitativo y cualitativo-. Entre la remediación y la recomposición habrá una relación de graduación.

46 "Lo censurable es precisamente el fundamentalismo neoconservador de querer absolutizar el mercado, reduciendo de esa forma todo el desafío de la sustentabilidad a una cuestión de asignación de "precios correctos" a la naturaleza. Por supuesto, es mejor tener alguna noción del valor económico que poseen los bienes y servicios ambientales, por más arbitraria que sea ésta, que no disponer de ninguna herramienta que asista a la toma de decisiones en esa área. Como dice Paul Hawken, "mientras no existe ningún modo 'correcto' para valorar un bosque o un río, sí existe una forma incorrecta, que es no asignar ningún valor" (Prugh et al., 1995: XV)”. Guimarães, R. La ética de la sustentabilidad y la formulación de políticas de desarrollo. Pág. 57. 
amplificada de los derechos (de una faz netamente individual a una mirada social-colectiva), como es el derecho de una reparación plena, integral y efectiva de quienes están afectados y discriminados socio-territorialmente, por arrastrar un legado de contaminación histórica, tendientes a revertir esa desigualdad ambiental y garantizar que esa situación de desprotección no se vuelva a repetir (Morales Lamberti, 2015: 161).

\section{Bibliografía}

Cardoso, A. (2016). Pasivos ambientales de la minería de carbón en Colombia: una aproximación desde la ecología política. Ecología Política, 94-98.

DoronI, G. (2017, enero-marzo). ¿Podemos hablar del principio de estado de derecho ambiental? Revista de Derecho Ambiental, 49, 109-122. Abeledo Perrot.

Doroni, G. (2017, 17 agosto). Hacia la posible configuración del principio de Estado de Derecho Ambiental (Parte I), Diario DPI-Diario Ambiental, 165.

Doroni, G.; Pezzano, L. (2017, noviembre). Hacia la posible configuración de un orden público ambiental internacional. Revista Iberoamericana de Derecho Internacional y de la Integración, 47.

George, C.J (2012). Justicia intergeneracional: la satisfacción de las necesidades y no de la codicia. Recuperado en http://www.socialwatch.org/sites/default/files/JusticiaIntergeneracional2012_esp.pdf

Jordano Fraga, J. (2007, Madrid-mayo). La administración en el Estado Ambiental de Derecho. Revista de Administración Pública, 173, 101-141. Madrid.

Loperena Rota, D. (1998). Los principios del Derecho Ambiental. Madrid: Civitas.

Lorenzetti, R. (2008). Teoría del Derecho Ambiental. Buenos Aires: La Ley.

Morales lamberti, A. (2008). Gestión y Remediación de Pasivos Ambientales. Estudios de Derecho Ambiental, 1(1), 3-237. Córdoba.

(2015). Dimensión social y colectiva de los derechos humanos: relacionalidad e influencias del paradigma ambiental. En Cafferatta, N. (Dir.), Derecho Ambiental-Dimensión social (407-429). Santa Fe: Rubinzal-Culzoni.

(2015, Junio-Septiembre). Los derechos humanos en el Código Civil y Comercial, como fuente de integración hermenéutica y reconocimiento axiológico en la aplicación del derecho ambiental. En Revista de Derecho Ambiental, 45, 140-163.

Pizarro, R. D. (2008). Responsabilidad civil por daño ambiental. Tutela Jurídica del Medio Ambiente, Ediciones de la Academia Nacional de Derecho y Ciencias Sociales de Córdoba, XLV, 149-195.

Russi, D. y Martínez-Alier, J. (2002). Pasivos ambientales. Debates ambientales, (S/D) 107-112.

Sticca, María Alejandra (2013). Algunas reflexiones acerca del derecho al medio ambiente sano como derecho humano. En Rey Caro, E. (Coord.). El Derecho Internacional Público como norma de conducta de los Estados (311-338). Córdoba: Gráfica Trejo.

Unidad de Planificación Minero Energética (UPME) (2002). Metodología para la valorización de pasivos ambientales en el sector eléctrico. Colombia. 